\title{
Prospective audit of the introduction of laparoscopic cholecystectomy in the west of Scotland
}

G M Fullarton, G Bell, and the west of Scotland laparoscopic cholecystectomy audit group

\begin{abstract}
Although laparoscopic cholecystectomy has rapidly developed in the treatment of gall bladder disease in the absence of controlled clinical trial data its outcome parameters compared with open cholecystectomy remain unclear. A prospective audit of the introduction of laparoscopic cholecystectomy in the west of Scotland over a two year period was carried out to attempt to assess this new procedure. A total of 45 surgeons in 19 hospitals performing laparoscopic cholecystectomy submitted prospective data from September 1990-1992. A total of 2285 cholecystectomies were audited (a completed data collection rate of $99 \%$ ). Laparoscopic cholecystectomy was attempted in $1683(74 \%)$ patients and completed in 1448 patients (median conversion rate to the open procedure $17 \%$ ). The median operation time in the completed laparoscopic cholecystectomy patients was 100 minutes (range 30-330) and overall hospital stay three days (1-33). There were nine deaths $(0 \cdot 5 \%)$ after laparoscopic cholecystectomy although only two were directly attributable to the laparoscopic procedure. In the laparoscopic cholecystectomy group there were 99 complications $(5 \cdot 9 \%), 53$ $(3 \%)$ of these were major requiring further invasive intervention. Forty patients $(2 \cdot 4 \%)$ required early or delayed laparotomy for major complications such as bleeding or bile duct injuries. There were $11(0 \cdot 7 \%)$ bile duct injuries in the laparoscopic cholecystectomy series, five were noted during the initial procedure and six were recognised later resulting from jaundice or bile leaks. Ductal injuries occurred after a median of 20 laparoscopic cholecystectomies. In conclusion laparoscopic cholecystectomy has rapidly replaced open cholecystectomy in the treatment of gall bladder disease. Although the overall death and complication rate associated with laparoscopic cholecystectomy is similar to open cholecystectomy, the bile duct injury rate is higher.

(Gut 1994; 35: 1121-1126)
\end{abstract}

Laparoscopic cholecystectomy has rapidly emerged as the most popular treatment option for the patient with gall stones. ${ }^{1-7}$
Despite the widespread acceptance of this new technique there have been no formal comparisons of laparoscopic cholecystectomy with conventional cholecystectomy. Indeed the requirement for a controlled clinical trial of laparoscopic cholecystectomy and open cholecystectomy has been considered unethical. ${ }^{8}$

Only one controlled study with comparatively small numbers has compared laparoscopic with a small incision 'minicholecystectomy' and this study showed an advantage for the laparoscopic procedure in terms of more rapid return to normal activities. ${ }^{9}$ Initial uncontrolled reviews of laparoscopic cholecystectomy have shown significant patient benefit in terms of reduced wound pain and shortened hospital stay ${ }^{70-13}$ but at the expense of an increased bile duct injury rate r $^{10}$ compared with previous data from conventional cholecystectomy. These uncontrolled studies while accumulating large numbers of patients have been selective, assessing up to $88 \%$ only of all cholecystectomies performed. ${ }^{7}$ The outcome and safety of laparoscopic cholecystectomy in treating gall stone disease therefore remain unclear.

In this report we describe a prospective audit of the introduction of laparoscopic cholecystectomy in the west of Scotland. The main aim of this study was to examine the safety and efficacy of laparoscopic cholecystectomy in current surgical practice.

\section{Methods}

The west of Scotland serves a population of 2422130 and is covered by 15 NHS hospitals (six teaching, nine district general) and four private hospitals. A group of west of Scotland surgeons met in September 1990 and agreed to prospectively audit all laparoscopic cholecystectomies in the region over a two year period. After this meeting a total of 45 surgeons in $15 \mathrm{NHS}$ and four private hospitals cooperated in the data collection as the west of Scotland laparoscopic cholecystectomy audit group. This represented $100 \%$ of the surgeons performing laparoscopic cholecystectomy in the participating hospitals. Individual surgeons contributed patient data from their first laparoscopic procedure until the study was terminated in September 1992. Each surgeon contributed patient data, however, on all cholecystectomies performed over the two year study period - that is, from day 1 (first laparoscopic procedure) to termination of 
study in September 1992. Data were collected on a standard proforma but complete collection of audit data was achieved by a research nurse who visited all participating hospitals, reviewed the operating theatre record books, and completed the documentation from individual patient case sheets. The close cooperation between surgical units in the west of Scotland also facilitated data collection.

To ensure standardisation it was agreed that a complication should be defined as any postoperative problem that delayed hospital discharge or required further treatment, or both. These were further subdivided into: (1) major - a complication that required further open surgery or invasive intervention (radiological and/or endoscopic), or both; (2) minor - a complication that delayed discharge or required further non-operative treatment, or both.

A conversion from laparoscopic to open cholecystectomy was only regarded as a complication if this was performed for urgent reasons such as haemorrhage, bile duct or bowel injury. Overall complete data collection was achieved in $99 \%$ of all cholecystectomies performed over the study period.

\section{PATIENTS}

The 45 surgeons performed a total of 2285 cholecystectomies over the two year period. Laparoscopic cholecystectomy was started in 1683 patients, median age 48 years (range 16-87) and completed laparoscopically in 1448 patients $(86 \%)$. For each surgeon the proportion of patients having laparoscopic cholecystectomy was $74 \%$ (median) (range $30-99)$. In the laparoscopic group $97 \%$ of patients had cholelithiasis, $2 \%$ had acalculous cholecystitis, $0.6 \%$ had gall bladder polyps, and $0.2 \%$ had suspected biliary dyskinesia. In $0 \cdot 2 \%$ of cases the diagnosis before operation was not stated. The median conversion rate to open cholecystectomy was $17 \%$ (range 0-45).

Six hundred and two $(26 \%)$ patients (median age 56 years (19-88)) had open cholecystectomy as the initial procedure. The commonest reason for patients having an open cholecystectomy was choledocholithiasis (27\%), a requirement for other surgery $(18 \%)$ followed by previous abdominal surgery (8\%), laparoscopic equipment problems $(5 \%)$, and obesity $(4 \%)$. Sixteen per cent of patients were recruited to a concomitant 'mini'-cholecystectomy study. In $22 \%$ of cases the reason for open cholecystectomy was not stated.

\section{Results}

\section{OPERATIVE TECHNIQUE}

Laparoscopic dissection of the gall bladder bed was by diathermy in $95 \%$ of patients, $5 \%$ of patients had dissection by laser (one surgeon).

Of the 1448 completed laparoscopic cholecystectomies 133 (9\%) had operative cholangiograms performed compared with
272 of 602 patients (45\%) having open cholecystectomy.

\section{OPERATIVE TIME}

Of the 1448 patients completing laparoscopic cholecystectomy the median operation time was 90 minutes (range 30-330). In the 235 patients having open conversion from the laparoscopic procedure the median operation time was 105 minutes (30-270). The median operation time for open cholecystectomy in this series was 75 minutes (range 25-345).

\section{OPERATIVE FINDINGS}

\section{Laparoscopic}

Of the 1448 cases completing laparoscopic cholecystectomies, $46 \%$ had a normal looking gall bladder; $32 \%$ exhibited signs of chronic cholecystitis; $7 \%$ of gall bladders seemed contracted and fibrosed; $3.5 \%$ were acutely inflamed, $2 \cdot 2 \%$ had mucoceles, and $1 \%$ of patients had empyemata. In $8 \%$ of cases the operative findings were not described. In 10 cases there was unexpected pathology findings. These were cirrhosis (2), pelvic inflammatory disease (2), healed duodenal ulcer perforations (2), liver metastases (1), choledochal cyst (1), hepatic cyst (1), and a Morgagni hernia (1).

\section{Common bile duct stones}

Overall $151(10 \%)$ of patients having laparoscopic cholecystectomy had an endoscopic rectrograde cholangiopancreatography (ERCP) before operation and 42 had an endoscopic sphincterotomy for bile duct stones. Thirty one patients had a postoperative ERCP for suspected retained stones $(n=22)$ or bile duct injuries $(n=9)$.

At laparoscopic cholecystectomy nine patients had stones identified by operative cholangiography. Three patients had conversion to open cholecystectomy with duct exploration. Six patients had postoperative ERCP with four having stones confirmed by this examination and cleared after endoscopic sphincterotomy.

\section{HOSPITAL STAY}

The patients having completed laparoscopic cholecystectomy were discharged from hospital after three days (range 0-72) compared with nine days (range 1-177) in those having open cholecystectomy.

RETURN TO WORK OR NORMAL ACTIVITIES Patients returned to work or normal activities at a median of 12 days (1-144) after laparoscopic cholecystectomy compared with 35 days (2-161) after open cholecystectomy.

REASONS FOR CONVERSION TO THE OPEN PROCEDURE $(n=235)$

The requirement for conversion to an open 
TABLE I Reasons for conversion to open cholecystectomy $(n=235)(\%)$

\begin{tabular}{lrlr}
\hline Urgent $(n=29)$ & \multicolumn{3}{l}{ Elective $(n=206)$} \\
\hline Haemorrhage & $21(72)$ & Adhesions & $74(36)$ \\
Bile duct damage & $5(17)$ & Acute inflammation & $45(22)$ \\
Bowel injury & $3(10)$ & Ill defined anatomy & $45(22)$ \\
& & Obesity & $12(6)$ \\
& & Insufflation problems & $12(5)$ \\
& & Instrument failure & $5(2 \cdot 5)$ \\
& Gall bladder leak & $5(2 \cdot 5)$ \\
& & Duct stones & $3(1 \cdot 5)$ \\
& & Others & $5(2 \cdot 5)$ \\
\hline
\end{tabular}

cholecystectomy was divided into 'urgent' and 'elective' categories. 'Urgent' conversions were designated for laparoscopic procedures where a complication (bile duct damage, haemorrhage or trocar/instrument induced organ damage) had occurred necessitating immediate conversion. 'Elective' conversions were designated for laparoscopic procedures where it was deemed safer to convert to open procedure because of intra-abdominal adhesions, severe inflammation, access or instrument problems or the presence of bile duct stones on operative cholangiography.

Of the 29 patients having 'urgent' conversions, 21 had bleeding as the primary reason for conversion (Table I). Five patients had bile duct injuries and three had bowel injuries noted at the time of laparoscopic cholecystectomy leading to conversion.

There were 206 'non-urgent' conversions to open cholecystectomy (Table I). The commonest reasons were intra-abdominal adhesions (36\%), acute inflammation $(22 \%)$, and ill defined anatomy (22\%) (Table I).

\section{MORTALITY}

There were 14 deaths $(0.6 \%)$ in the 2285 cholecystectomies performed over the study period. Nine deaths $(0.5 \%)$ occurred after laparoscopic cholecystectomy although four of these occurred in patients who had conversions to the open procedure (Table II). Five patients $(0.3 \%)$ died after laparoscopic cholecystectomy alone (Table II). Of these only one could be directly attributable to the laparoscopic procedure.

Five patients $(0 \cdot 8 \%)$ died after open cholecystectomy.

TABLE II Mortality after laparoscopic cholecystectomy ( $n=9)(0 \cdot 5 \%)$

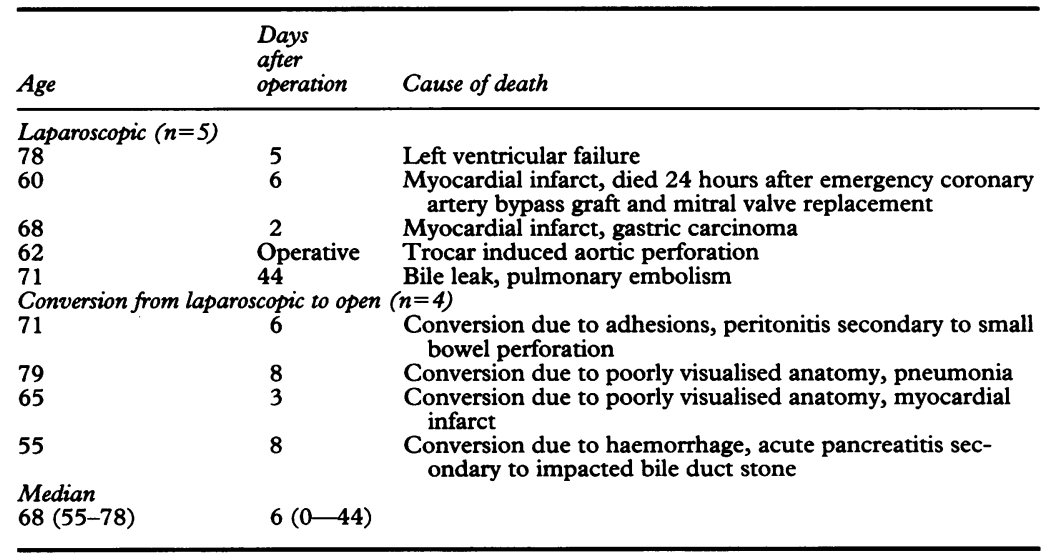

\section{COMPLICATIONS}

There were 99 complications $(5.9 \%)$ noted in 1683 patients undergoing laparoscopic cholecystectomy (Table III). The complication was deemed major in 53 patients $(3 \%)$ with 29 patients $(1.7 \%)$ requiring urgent conversion for haemorrhage, bile duct or bowel injury (Table III). Of the remaining patients with major complications, 11 required delayed laparotomy for bile duct injuries (4), peritonitis secondary to bowel injury (3), haemorrhage (2), or strangulated incisional hernias (2). Overall, therefore, 40 patients $(2 \cdot 4 \%)$ required a laparotomy for complications developing during or after laparoscopic cholecystectomy. Forty six patients had minor complications $(2 \cdot 8 \%)$ after laparoscopic cholecystectomy (Table III).

\section{SEX AND CONVERSION RATE}

The overall conversion rate from laparoscopic to open cholecystectomy was higher in male patients 69/326 (21\%) compared with female patients $166 / 1357(12 \%)(p<0.002)\left(\chi^{2}\right.$ test). The complication rates, however, after laparoscopic cholecystectomy were similar in women (6\%) compared with men (5\%).

\section{BILE DUCT INJURIES}

There were $11(0 \cdot 7 \%)$ bile duct injuries in this series of laparoscopic cholecystectomies (Table IV), five of these were recognised intraoperatively and this resulted in immediate conversion to the open procedure with either hepaticojejunostomy or primary duct repair and $T$ tube drainage being performed. In six patients the bile duct injury was only recognised postoperatively by the development of a biliary fistula $(n=4)$ or progressive jaundice $(n=2)$. In four of these patients laparotomy was performed at a median of seven days (range 6-30), after initial cholecystectomy with either biliary-enteric bypass or simple repair being performed. Two patients with bile duct strictures were treated by endoscopic biliary stent insertion (Table IV).

The 11 bile duct injuries were incurred by 10 surgeons (nine consultants, one senior registrar) after a median of 20 laparoscopic cholecystectomies (range 3-51). Operative cholangiography was performed in two of these patients and this was after the ductal injuries had occurred. Two bile duct injuries $(0.3 \%)$ occurred in patients having an open cholecystectomy.

\section{Discussion}

Laparoscopic cholecystectomy has been rapidly accepted by patients and surgeons as the preferred procedure for the treatment of gall stones. ${ }^{1-5}{ }^{10-14}$ Its progression has been unchecked by the usual constraints of assessment by controlled clinical trial because of its widespread, largely unchallenged, acceptance by the surgical profession. The advantages of laparoscopic cholecystectomy include reduced wound pain, lack of scarring, and reduced 
TABLE III Complications of laparoscopic cholecystectomy in 1683 patients

\begin{tabular}{lrl}
\hline & No & $\%$ Incidence \\
\hline Major (n=53) & & \\
Urgent conversions: & 21 & $1 \cdot 2$ \\
$\quad$ Haemorrhage & 5 & $0 \cdot 3$ \\
$\quad$ Bile duct injury & 3 & $0 \cdot 2$ \\
Bowel injury & 6 & $0 \cdot 4$ \\
Bile duct injuries & 7 & $0 \cdot 4$ \\
Bile collections & 4 & $0 \cdot 2$ \\
Incisional hernias & 3 & $0 \cdot 18$ \\
Peritonitis (bowel injury) & 2 & $0 \cdot 1$ \\
Haemorrhage & 1 & $0 \cdot 06$ \\
Subphrenic abscess & 1 & $0 \cdot 06$ \\
Cholangitis & & \\
Minor $(n=46)$ & 8 & $0 \cdot 5$ \\
Wound infection & 7 & $0 \cdot 4$ \\
Wound haematoma & 7 & $0 \cdot 4$ \\
Minor bile collections & 5 & $0 \cdot 4$ \\
Urinary retention & 5 & $0 \cdot 4$ \\
Urinary tract infection & 4 & $0 \cdot 2$ \\
Chest infections & 4 & $0 \cdot 2$ \\
Retained stones & 3 & $0 \cdot 18$ \\
Pneumothorax & 3 & $0 \cdot 18$ \\
Atrial fibrillation & 99 & $5 \cdot 9$ \\
Total & & \\
\hline
\end{tabular}

hospital stay with earlier return to work or normal activity. The major drawback of the laparoscopic procedure relates to its apparent higher bile duct injury rate compared with the open procedure. ${ }^{7} 10$

In this large prospective audit of laparoscopic cholecystectomy in a defined west of Scotland population we hoped to answer some questions relating to the safety and efficacy of laparoscopic cholecystectomy. In this series we have collected data in $99 \%$ of all cholecystectomies performed by all the surgeons in the participating hospitals who undertake laparoscopic cholecystectomy. This is therefore a true reflection of cholecystectomy practice during each surgeons introduction to laparoscopic cholecystectomy. The data collection was aided by the close cooperation and geographical location of the surgical units in the west of Scotland.

It is clear from this study that the trend to laparoscopic surgery for gall stone disease is rapid and probably now unstoppable. Overall $74 \%$ of patients with gall bladder disease in this series had laparoscopic cholecystectomy with this figure rising to $88 \%$ in those surgeons with more than two years laparoscopic experience.

The benefits of laparoscopic cholecystectomy are clear from this audit. Most patients were discharged home from hospital after their laparoscopic cholecystectomy at three days

TABLE IV Bile duct injuries after laparoscopic cholecystectomy $(n=11)(0 \cdot 7 \%)$

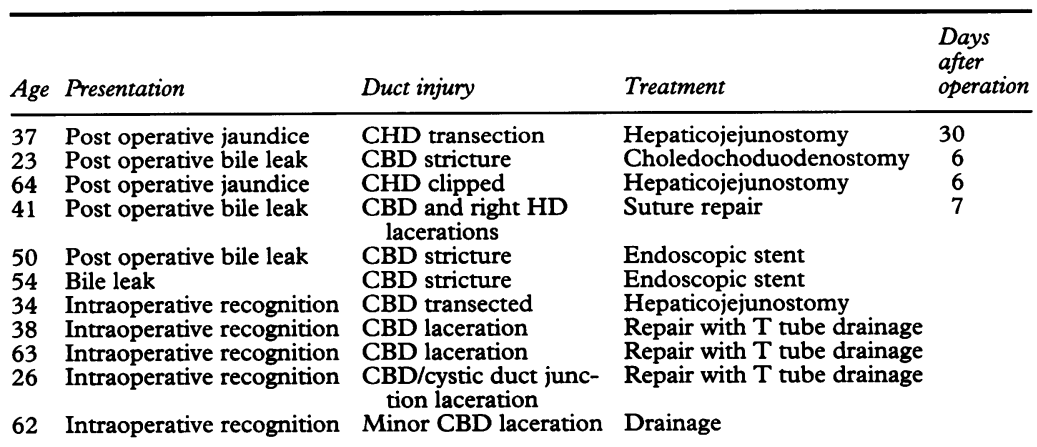

Median age 38 years (23-64). $\mathrm{CHD}=$ common hepatic duct, $\mathrm{HD}=$ hepatic duct, $\mathrm{CBD}=$ common bile duct. with most patients returning to work or normal activities by 12 days. We have recently shown that such clear patient benefits are accompanied by direct cost savings to hospitals by adopting laparoscopic cholecystectomy. ${ }^{15}$

The overall morbidity associated with laparoscopic cholecystectomy $(6 \%)$ is similar compared with the open procedure, which has reported morbidity rates of 5-25\%. ${ }^{16-19}$ In this series, $53 \%$ of our complications were important requiring therapeutic intervention with either further surgery or interventional radiology; haemorrhage being the commonest complication requiring urgent conversion to the open procedure. The commonest minor complication in this series was wound infection, which occurred despite antibiotic prophylaxis. Some complications noted are unique to laparoscopic surgery. Three patients in this study had visceral damage related to cannula insertion after induction of the pneumoperitoneum. These injuries may be avoided by the insertion of the initial port under direct vision as with the Hasson cannula - that is, open laparoscopy. ${ }^{20}$ The four complications of incisional hernias through a cannula site can also be avoided by direct fascial closure at completion of laparoscopy.

The major concern relating to laparoscopic cholecystectomy has been the increased bile duct injury rate compared with the open procedure. Although this was higher at $0.5 \%$ in a large series of laparoscopic cholecystectomies ${ }^{7}$ compared with the figure for open cholecystectomy of $0-0 \cdot 4 \% \%^{18} 12^{21-23}$ the overall duct injury rate remains unknown but of concern. ${ }^{24-26}$ In our series the bile duct injury rate is also significantly higher than the previously established figure for open cholecystectomy. Bile duct injuries occurred during open cholecystectomy caused by dissection in poorly visualised areas with unclear anatomy ${ }^{27-29}$ and such factors seem to pertain in the laparoscopic procedure.

Certain patterns of bile duct injury during laparoscopic cholecystectomy are emerging. Firstly, excessive cystic duct traction may tent the common bile duct and lead to misidentification of this structure for the cystic duct with clipping or resection of the common bile duct and often right hepatic artery injury. ${ }^{30}$ Secondly, inadvertent clipping of the bile duct may occur during hilar bleeding and thirdly thermal and ischaemic ductal injury through either injudicious use of diathermy or excessive dissection of the cystic/common bile duct junction. ${ }^{25} 31$ The requirement for surgeons to operate in a two dimensional field certainly contributes to misidentification of important structures and the recent development of three dimensional imaging may help reduce this risk.

With open cholecystectomy the risk of bile duct injury was highest between the surgeons 25 th and 100th procedure ${ }^{23}$ and this early period also seems to be the laparoscopists most vulnerable with a bile duct injury at a median of 20 procedures noted in the current study.

The role of operative cholangiography in prevention of bile duct injuries in open cholecystectomy is unclear although most 
authorities accept that an accurate biliary 'road map' is at least likely to offer some help in their prevention. ${ }^{24} 2532$ In this series it is notable that operative cholangiography was performed in only $9 \%$ of patients having laparoscopic cholecystectomy compared with $45 \%$ of open cholecystectomy patients showing a change in surgical practice. In addition, of the 11 ductal injuries after laparoscopic cholecystectomy only two had operative cholangiography and this was performed after the injury had been produced. In a newly developing procedure such as laparoscopic cholecystectomy, which seems to carry an increased risk of bile duct injury it seems sensible that more frequent operative cholangiography should be performed particularly if the anatomy is in any way unclear.

The avoidance of bile duct injury during laparoscopic cholecystectomy may also require more closely regulated supervision of trainee laparoscopists particularly during their early 'learning curve' period. In addition patients with severe cholecystitis or previous abdominal surgery may be best treated by conventional open cholecystectomy from the outset. In difficult cases, however, where laparoscopy has been initiated perhaps a lower threshold for conversion to the open procedure would now seem appropriate. Retrograde dissection of the gall bladder in severe inflammation may also be helpful in decreasing the likelihood of ductal injuries.

The death rate in this unselected series of laparoscopic cholecystectomy stands at $0.5 \%$, which is comparable with open cholecystectomy series. Of the nine deaths only the aortic perforation can be directly attributable to the laparoscopic procedure, although the small bowel perforation in the converted patient could have been a laparoscopic injury. Both aortic and bowel perforation are clearly technically avoidable complications especially if open laparoscopy is performed.

The treatment of bile duct stones with the advent of laparoscopic cholecystectomy remains controversial. At present the technique of laparoscopic common bile duct exploration and stone retrieval remains feasible in only a few highly experienced centres worldwide. With this proviso, surgeons in this study initially regarded choledocholithiasis as an indication for an open cholecystectomy. A significant number of patients with choledocholithiasis, however, have now been treated by a minimally invasive combination treatment of preoperative ERCP, endoscopic sphincterotomy, stone clearance, and subsequent laparoscopic cholecystectomy. Unless bile duct exploration techniques become clearly established this combination seems to be the most acceptable.

We conclude that laparoscopic cholecystectomy is rapidly replacing open cholecystectomy as the preferred treatment for patients with gall bladder disease. In this introductory period, although clear patient benefits exist, there is an increased risk of major bile duct injury with laparoscopic cholecystectomy. More judicious patient selection, increased use of cholangiography, and earlier conversion to open procedure may be helpful in decreasing the ductal injury rate after laparoscopic cholecystectomy.

We wish to thank Mrs Helen Leslie, audit nurse, Inverclyde Royal Hospital, for help in this study and Mrs Annette Bowie for her secretarial assistance.

1 Reddick EJ, Olsen DO. Laparoscopic laser cholecystectomy. Surg Endosc 1989; 3: 131-3.

2 Dubois F, Berthelot G, Levard H. Cholecystectomie par coelioscopeie. Presse Med 1989; 18: 980-2.

3 Dubois F, Icard P, Berthelot G, Levard H. Coelioscopic cholecystectomy. Preliminary report of 36 cases. Ann Surg 1990; 211: 60-2.

4 Perissat J, Collet DR, Belliard R. Gallstones: laparoscopic treatment, intracorporeal lithotripsy followed by cholecystreatment, intracorporeal lithotripsy followed by cholecystostomy or cholecystectomy - a pers
Endoscopy 1989; 21 (suppl 1): 373-4.

5 Zucker K, Bailey RW, Gadacz TR, Imbembo AL. Laparoscopic guided cholecystectomy. Am f Surg 1991; 161: $36-44$

6 Nathanson LK, Shimi S, Cuschieri A. Laparoscopic cholecystectomy: The Dundee Technique. Br f Surg 1991; 78: 155-9.

7 The Southern Surgeons Club. A prospective analysis of 1518 laparoscopic cholecystectomies. N Engl f Med 1991; 324: $1073-8$.

8 Neugebauer E, Troidl H, Spangenberger W, Dietrich A, Lefering $R$, and The Cholecystectomy Study Group. Lefering $R$, and The Cholecystectomy Study Group. the randomised controlled trial. Br f Surg 1991; 78: the rando 150 .

9 Barkun JS, Barkun AN, Sampalis JS, Fried G, Taylor B, Wexler MJ, et al. Randomised controlled trial of laparoscopic versus mini cholecystectomy. Lancet 1992; 340: 1116-9.

10 Peters JH, Ellison EC, Innes JT, et al. Safety and efficacy of laparoscopic cholecystectomy. A prospective analysis of 100 initial patients. Ann Surg 1991; 213: 3-12.

11 Spaw AT, Reddick EJ, Olsen DO. Laparoscopic laser cholecystectomy: analysis of 500 procedures. Surg Laparoscop Endosc 1991; 1: 2-7.

12 Wilson P, Leese T, Morgan WP, Kelly JF, Brigg JK. Elective laparoscopic cholecystectomy for 'all-comers'. Llective laparoscopic chol 1991 ; 338: 795-7.

13 Grace PA, Quereshi A, Coleman J. Reduced post operative hospitalisation after laparoscopic cholecystectomy. $B r f$ Surg 1991; 78: 160-2.

14 Holohan TV. Laparoscopic cholecystectomy. Lancet 1991; 338: 801-3.

15 Fullarton GM, McMillan R, Darling K, Bell G. Evaluation of the cost of laparoscopic and open cholecystectomy [Abstract]. Gut 1992; 33 (suppl 1): 517.

16 Glen F, McSherry CK, Dineen P. Morbidity of surgical treatment for non-malignant biliary tract diseases. Surg Gynecol Obstet 1968; 126: 15-26.

17 Scher KS, Scott-Conner CE. Complications of biliary surgery. Am Surg 1987; 53: 16-21.

18 Davies MG, O'Brien E, Mannion C, et al. Audit of open cholecystectomy in a District General Hospital. Br $\mathcal{F}$ Surg 1992; 79: 314-9.

19 Herzog U, Messmer P, Sutter M, Tondelli P. Surgical treatment for cholelithiasis. Surg Gynecol Obstet 1992; 175: 238-92.

20 Hasson HM. Modified instrument and method for laparoscopy. Am F Obstet Gynecol 1971; 110: 886-7.

21 Gilliland TM, Travers LW. Modern standards for comparison of cholecystectomy with alternative treatments for symptomatic cholelithiasis with emphasis on long term relief of symptoms. Surg Gynecol Obstet 1990; 170: 39-44.

22 Smith EB. Iatrogenic injuries to extrahepatic bile ducts and associated vessels; a 25 year analysis. $\mathcal{F}$ Natl Med Assoc 1982; 74: 735-8.

23 Andren-Sandberg A, Alindeer G, Bengmark S. Accidental lesions of common bile duct at cholecystectomy. Ann Surg lesions of common bile.

24 Way LW. Bile duct injury during laparoscopic cholecystectomy. Ann Surg 1992; 215: 195.

25 Mossa AR, Easter DW, Van Sonnenberg E, Casola G, D'Agostino $H$. Laparoscopic injuries to the bile duct - a cause for concern. Ann Surg 1992; 215: 203-8.

26 Altman LK. Surgical injuries lead to new rule. New York assails the training for a popular technique. New York Times 1992; June 14: 1

27 Bismuth $\mathbf{H}$. Post-operative strictures of the bile duct. In: Blumgart LH, ed. The biliary tract. Clinical surgery interna tional. Vol 5. Edinburgh: Churchill Livingstone, 1982. 209-18.

28 Kune GA. Bile duct injury during cholecystectomy. Causes, prevention and surgical repair. Aust NZ $\mathcal{F}$ Surg 1979; 49: preven 40 .

29 Garden OJ. Iatrogenic injury to the bile duct. Br f Surg 1991; 78: 1412-3.

30 Peters JH, Gibbons G, Innes JT, et al. Complications of laparoscopic cholecystectomy. Surgery 1991; 110: 769-78.

31 Davidoff AM, Pappas TN, Murray EA, et al. Mechanisms of major biliary injury during laparoscopic cholecystectomy. Ann Surg 1992; 215: 196-202. 
32 Berci G, Sackier JM, Paz-Partlow M. Routine or selected intraoperative cholangiography during laparoscopic cholecystectomy? Am $\mathcal{F}$ Surg 1991; 161: 355-60.

The west of Scotland laparoscopic cholecystectomy audit Troup: Mr W R Murray, Mr C W Imrie, Mr J R Anderson, Mr I N Baxter, Glasgow Royal Infirmary; Mr P O'Dwyer, Mr G Ramsay, Western Infirmary, Glasgow; Mr D Galloway, Mr A McKay, Gartnavel General Hospital, Glasgow; Mr I S Smith, Mr D T Hansell, Stobhill Hospital, Glasgow; Mr A Mack, Mr D C Smith, Mr I
Infirmary, Glasgow. Districts: Mr P J Shouler, Mr E W Taylor, Mr J R McCallum, Vale of Leven District General Hospital, Alexandria, Dunbartonshire; Mr G Bell, Mr J J Morrice, Mr G Orr, Mr I Watt, Mr D Hamilton, Inverclyde Royal Hospital, Greenock; Mr K G Mitchell, Mr B W A Williamson, Royal
Alexandra Hospital, Paisley; Mr A D McNeill, Mr A Smith, Mr Alexandra Hospital, Paisley; Mr A D McNeill, Mr A Smith, Mr W S Hendry, Mr D B Booth, Stirling Royal Infirmary, Stirling; Mr C Moran, Mr B A Sugden, Crosshouse Hospital, Brookes, Monklands District General Hospital, Airdrie; Mr J Wallace, Law Hospital, Carluke, Lanarkshire; Mr H Campbell, Stonehouse Hospital, Stonehouse, Lanarkshire; Mr D G Knight, Mr J R Richards, Mr J R Goldring, Mr W O Thomson, Hairmyres Hospital, East Kilbride, Glasgow. 